\title{
HCFL Lamp Only Lights Up under Coexistence of Cathode and Anode in Ar Gas Space for Half Cycle of AC Driving Circuit
}

\author{
Lyuji Ozawa \\ Beijing, China \\ Email: rotsun4@126.com
}

How to cite this paper: Ozawa, L. (2019) HCFL Lamp Only Lights Up under Coexistence of Cathode and Anode in Ar Gas Space for Half Cycle of AC Driving Circuit. Journal of Power and Energy Engineering, 7, 1-13.

https://doi.org/10.4236/jpee.2019.72001

Received: December 20, 2018

Accepted: January 28, 2019

Published: January 31, 2019

Copyright () 2019 by author(s) and Scientific Research Publishing Inc. This work is licensed under the Creative Commons Attribution International License (CC BY 4.0).

http://creativecommons.org/licenses/by/4.0/

\begin{abstract}
Vacuum space between Ar atoms in unlighted HCFL lamps is an electric insulator, because vacuum fills up with strong negative electric field from orbital electrons in ${ }^{3} \mathrm{p}_{6}$ electron shell of Ar atoms. Vacuum space in lighted $\mathrm{FL}$ lamps changes to the neutral vacuum that provides a superconductive vacuum for moving electrons at above room temperature. The complications of lighting mechanisms of HCFL lamps for more than 80 years have clearly solved with coexistence of disparate external and internal electric circuits for each half cycle. External electric circuit acts as two roles. One helps for formation of internal electric circuit in Ar gas space by electric field. Other picks up induced voltages from capacitor $\mathrm{C}_{\mathrm{FL}}$. HCFL lamp only lights up with moving electrons in internal DC driving circuit. Electrons in HCFL lamp only move from cathode to anode, which respectively have negative and positive potentials against grand $(\mathrm{V}=0)$, and which are formed with volumes of heated corona light $(4 \mathrm{G})$ at around $\mathrm{W}$-filament metal electrodes with a help of heated $\mathrm{BaO}$ particles. The HCFL lamp that emits thermoelectrons is a false story. Here we have totally revised the fundamentals of the lighting mechanism of the established HCFL lamps for last 80 years.
\end{abstract}

\section{Keywords}

FL Lamp, Cathode and Anode, Superconductive Vacuum, Operation Life

\section{Introduction}

Human have daytime activity for more than 5 million yeas under slightly overcastted sky by thin clouds. Naked eyes of human adjust to daytime sceneries that continuously generate $10^{25}$ visible photons $\left(\mathrm{m}^{2}, \mathrm{~s}\right)^{-1}$; corresponding to luminance $\left(300 \mathrm{~cd}, \mathrm{~m}^{-2}\right)$ or illuminance $\left(300 \mathrm{~lm}, \mathrm{~m}^{-2}\right)$. The human activities extended to 
nighttime with the illumination of dark. First illumination source was the fire flame by chemical reactions with oxygen in air. The heated temperatures of fire flame are determined by amount of change in entropy. Illumination by fire flame has been called as the candescent lamps. The word of the candescence comes from ancient Greek that means fire flame. After finding of invisible electrons and atoms in materials and in gases, the light sources shift to the incandescent lamps that do not use fire flame. If you refer Webster's Dictionary, the incandescent lamp is defined with the $\mathrm{W}$-filament lamp that was the first incandescent lamp on early 1900s. After the W-filament lamp, the FL lamp and LED lamp have developed using gases and solids, respectively. If your brain is AI computer, you may assign only W-filament coil as the incandescent light source, and you never assign FL lamps and LED lamps as the incandescent lamps. Here we take the original definition of the incandescent lamp, not the Webster's Dictionary. The incandescent lamp does not use the fire flam. FL and LED lamps generate visible lights by moving electrons in gases and solids, respectively. Size of electron is $5.6 \times 10^{-15} \mathrm{~m}$, and size of atoms is around $10^{-9} \mathrm{~m}$. They are invisible sizes by the naked eyes. The study on the FL and LED lamps steps in the abstraction shown in Figure 1. The modern sciences have developed with the abstractions with the scientific evidences.

The lights from the incandescent lamps are generated by the moving electrons in metal, solid, and gases. Electron is a quantum. The figure of the merit of the incandescent lamps is given by the quantum efficiency $\left(\eta_{\mathrm{q}}\right)$. The $\eta_{\mathrm{q}}$ of the incandescent lamps is given by the numbers of the emitted visible photons per one moving electron in the incandescent lamps.

The W-filament metal lamp emits the lights which distribute from the UV lights to the infrared lights. We cannot determine the $\eta_{\mathrm{q}}$ of $\mathrm{W}$-filament lamp. The LED lamp is made with the solids. The LED lamp generates one visible photon by the recombination of a pair of injected electron and hole at the luminescence centers in the junction. The moving electron and hole in sold inevitably lose some amount of the kinetic energy by the Joule Heat (IR), resulting in the $\eta_{\mathrm{q}}<1.0$; many case $\eta_{\mathrm{q}} \approx 0.5$ [1] [2]. The commercial hotcathode (HC) FL lamp generates the light by electrons that move on in vacuum space between $\mathrm{Ar}^{1+}$. The positive electric field of $\mathrm{Ar}^{1+}$ neutralizes the negative electric field in the vacuum space in Ar gas. By the neutralization of the vacuum space, the electrons move on in the superconductive vacuum $(\mathrm{RI}=0)$ at above room temperature. Consequently, each moving electron in FL lamps has an astronomical $\eta_{\mathrm{q}}=$ $10^{12}$ photons $\left(\mathrm{m}^{3}, \mathrm{~s}\right)^{-1}$ [1] [2]. The numbers of the moving electrons in the internal DC electric circuit of the HCFL lamps are around $10^{13}$ electrons per second. Thus, one 40W-HCFL lamp emits $10^{25}$ photons per second $\left(=10^{12} \times 10^{13}\right.$ electrons). Hence, we can say that only FL lamp has a great advantage over the LED lamp for the energy saving incandescent lamps, even though some one claims that the LED lamps are the energy saving light source. With this reason, we have study on the details of the established HCFL lamps for more than 90 years. The 
studies have found the many false stories in the established technologies of the HCFL lamps. We will clarify them in this report.

The studies of the lighting Ar gas in the glass tubes have a long history. First lighting glass tube is called as the Geissler tube under the operation with the electrodes that are operated with the high frequencies on 1859. After 44 years later (1903), John Sealy Townsend had reported that as the vacuum pressure is below $10^{-3} \mathrm{~Pa}\left(10^{-5}\right.$ Torr), the needle metal electrode as cathode that has a few ten volts, emits electrons in to the vacuum, and the anode metal electrode collects the emitted electrons. This has called as the field emission of the electron in to vacuum from the needle electrode. However, as the Ar gas pressures higher than $10^{-1} \mathrm{~Pa}\left(>10^{-3}\right.$ Torr), the needle electrode does not emit the electron under the potential below $0.95 \mathrm{kV}$. He did not give the reason. We know the reason that the vacuum space in Ar gas fills up with the negative electric field from the ${ }^{3} \mathrm{p}_{6}$ orbital shell of Ar atom, as illustrated in Figure 2 [1].

The negative electric field is invisible by the eyes. Fortunately, we can detect the evidence of the negative electric field in the vacuum space between floating $\mathrm{Ar}$ atoms by the measurements of the absorption spectrum by a spectrometer. The details will show in Figure 2. Townsend gave us an important message. The massage is the lighting condition of the Ar gas space by the needle electrode.

Townsend made another experiment that is a very important result for the study on FL lamps. Above $1.0 \mathrm{kV}$, the needle electrode in the Ar gas at $931 \mathrm{~Pa}$ (7 Torr) is suddenly covered up with the volume of the glow light of the Ar atoms. He described that the volume of the glow light acted as the electron source (cathode) in the Ar gas space. In the Townsend tube having Ar gas at above $133 \mathrm{~Pa}$ (1 Torr), the needle electrode is covered with the volume of the glow light that is third generation $(3 \mathrm{G})$ electron source. The electrons move from the $3 \mathrm{G}$ cathode, that has the high negative potential against to the grand, (e.g., $>-1.0 \mathrm{kV})$, to the metal plate electrode that has $\mathrm{V}=0$. The volume of the glow light on the needle electrode acts as the electron emitter (cathode) and the emitted electrons are collected by the metal electrode (anode) that has the grand potential. It should be noted that the anode $(\mathrm{V}=0)$ never emits the electron in to the vacuum. Thus, Townsend clearly indicated the necessity of the cathode and anode for the moving electrons in the Ar gas space by the formation of the $3 \mathrm{G}$ volume with the external DC electric circuit. The FL lamp emits the sky-blue light that attributes to the excited $\mathrm{Ar}$ atoms $\left(\mathrm{Ar}^{*}\right)$. He did not show the reason why the insulating vacuum between Ar atoms changes to the electric conductive vacuum under the DC voltages above $1 \mathrm{kV}$ to the needle electrode.

However, after the Townsend report for more 100 years, the scientists and engineers who had studied the FL lamps never paid their attention to the Townsend report. This is because the scientists and engineers paid their attention to the Geissler tube with change of the name as the vacuum discharge lamps. Then, they had developed the hotcathode (HC) FL lamps. Their choice led them to a wrong path of the study on the HCFL lamps. The development processes of the 
HCFL lamps are the below:

After 67 years later from the Geissler tube, the HCFL lamps had invented by R. R. Machelet on 1926 [3] and by F. Meyer on 1928 [4] using the heated $\mathrm{W}$-filament coils with the $\mathrm{BaO}$ particles. The developed HCFL lamps are operated with AC diving circuit with $100 \mathrm{~V}$ with $50 \mathrm{~Hz}$. Then many scientists and engineers paid their attentions to the developed HCFL lamps. They have developed the commercial 40W-HCFL lamps in $3.2 \times 10^{-2} \mathrm{~m}$ outer diameter (T-10) with $1 \mathrm{~m}$ long. The annual production volume of the 40W-HCFL lamps on the world was over multimillions per year. Figure 3(A) shows the photo picture of the lighting 40W-HCFL lamp. As shown in Figure 3(B), the HCFL lamp is assembled with five components. They are 1) vacuum-sealed glass tube, 2) $\mathrm{W}$-filament coils with $\mathrm{BaO}$ particles at the both ends of the vacuum-sealed glass tube, 3) Ar gas at the pressure around $930 \mathrm{~Pa}$ (=7 Torr), 4) vaporized $\mathrm{Hg}$ atoms at around $0.1 \mathrm{~Pa}\left(\sim 10^{-3}\right.$ Torr), and 5) phosphor screen on inner wall on the vacuum-sealed glass tube as the converter from the UV lights to the visible lights. Then, they had studied the details of the lighting mechanisms of the 40W-HCFL lamps with their capabilities [5]-[10]. The systematic studies of the HCFL lamps in USA had terminated before 1980 with the reason that no room remains for the further improvement of the qualities of the HCFL lamps. With the large annual production volume for more than 50 years on the world, no one have a question on the established lighting mechanisms of the optimized 40W-HCFL lamps. Here, we have had a question on the lighting mechanisms of the 40W-HCFL lamps.

\section{No Existence of HCFL Lamps}

We have deeply studied with the thermoelectrons emission from the heated $\mathrm{BaO}$ particles in cathode ray tubes (CRT) and vacuum radio tubes (VRT). The heated $\mathrm{Ba}$ atoms on the $\mathrm{BaO}$ particles only emit thermoelectrons into the vacuum that is vacuum pressures below $10^{-3} \mathrm{~Pa}\left(<10^{-5}\right.$ Torr). In the vacuum pressure above $10^{-1}$ $\mathrm{Pa}\left(10^{-3}\right.$ Torr $)$, the heated $\mathrm{Ba}$ atoms instantly change to the $\mathrm{BaO}$ or $\mathrm{Ba}$ compounds that they do not emit the thermoelectrons in to vacuum.

However, the developers of the HCFL lamps have stubbornly believed that the commercial HCFL lamps use the thermoelectron emission from the heated $\mathrm{BaO}$ particles on the $\mathrm{W}$-filament coils for more than 80 years. The HCFL lamps contain (a) Ar gas at $930 \mathrm{~Pa}\left(=7\right.$ Torr) and (b) residual gases at around $1 \mathrm{~Pa}\left(=\sim 10^{-2}\right.$ Torr) [1] [2]. Therefore, the heated $\mathrm{BaO}$ particles never emit the thermoelectrons into the Ar gas space of the HCFL lamps. Anyhow, by the application of the $\mathrm{W}$-filament coils with the $\mathrm{BaO}$ particles to the HCFL lamps, the HCFL lamps brilliantly light up from the phosphor screen. We must find out the real reasons. The details will describe in next Section 3.

Individual Ar atoms in FL lamps isolate with the separation distance at $10^{-6} \mathrm{~m}$ [1] [2] as illustrated in Figure 2. The vacuum space between Ar atoms fills up with the negative electric field from the Ar atoms. The presence of the strong 
negative electric field in the vacuum space between Ar atoms can be detected by the measurement of the absorption spectrum by a high resolution spectrometer. The absorption spectrum consists with the sharp lines, indicating isolation of individual Ar atoms in FL lamp. Furthermore, the measurements inform us that the excited energy levels of Ar atoms split to sublevels by Stark Effect. The presence of the Stark Effect provides us a direct evidence of the presence of the strong electric field from the electrons in ${ }^{3} \mathrm{p}_{6}$ orbital shell of Ar atoms. Townsend had given the elimination of the negative electric field in the Ar gas by the formation of the volume of the glow light in the Ar gas space. In the HCFL lamps do not use the volume of the glow light, but the HCFL lamps use of the heated volumes of the corona light that is $4 \mathrm{G}$ electron sources on the $\mathrm{W}$-filament coils at the both sides as mentioned in Figure 3. The heated $4 \mathrm{G}$ by the corona lights is the same quality with the volume of the glow lights. For the lighting of the HCFL lamp, at first we must figure out how neutralize the negative electric field between Ar atoms in the Ar gas at around the heated W-filament coils for one cycle of AC driving circuit.

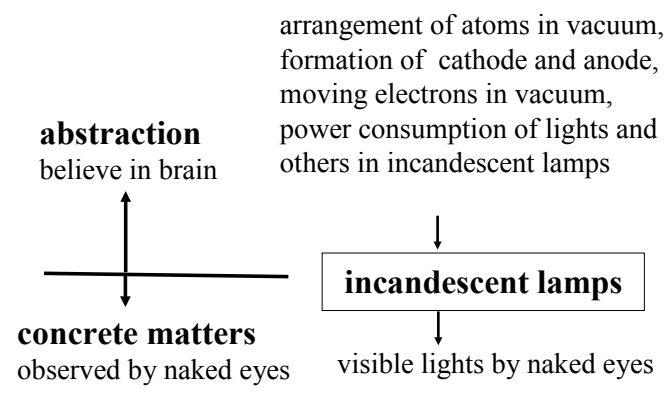

Figure 1. Illustration of abstract and concrete matters on study on incandescent lamps.

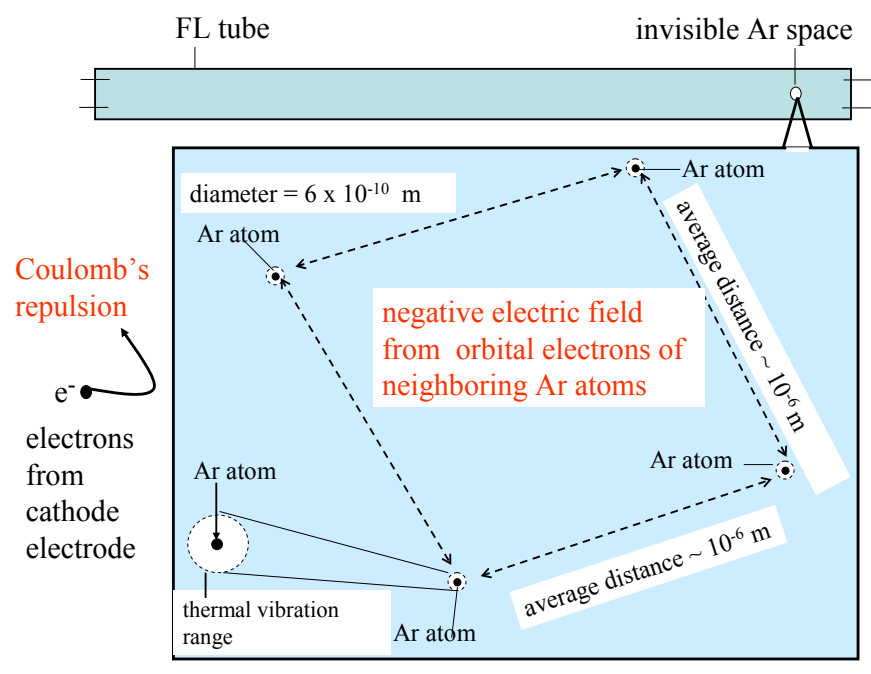

Figure 2. Schematic illustration of vacuum space between floating Ar atoms in vacuum in commercial HCFL lamp that has Ar gas pressure at $931 \mathrm{~Pa}(=7$ Torr $)$. 
emitted $\mathrm{Ar}$ and $\mathrm{Hg}$ atoms fluorescent lamp emitted $\mathrm{Ar}$ and $\mathrm{Hg}$ atoms

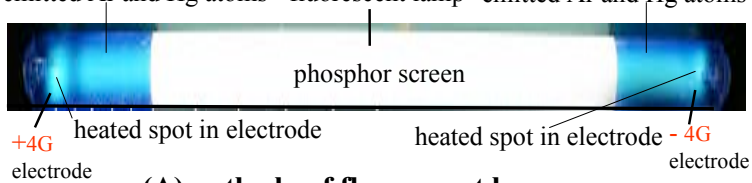

(A) outlook of fluorescent lamp

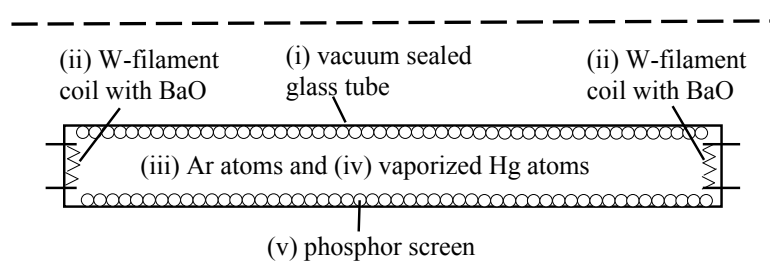

(B) materials in fluorescent lamp

Figure 3. Schematic illustration of HCFL lamp (A) is outlook of lighted HCFL lamp and (B) illustrates five components of HCFL lamp.

\section{Formation of Cathode and Anode of Internal DC Driving Circuit in Ar Gas Space in HCFL Lamp under AC Driving Circuit}

The HCFL lamps had basically developed with the concept of the Geissler tube. However, the study of the lighting mechanisms of the HCFL lamps must step in the most advanced science knowledge over the concept of the Geissler tube. The fundamental is the formation of cathode and anode in Ar gas space of FL lamp. The FL lamps only light up with the moving electrons from cathode to anode. As already mentioned, the $\mathrm{BaO}$ particles on the $\mathrm{W}$-filament coils never assign as the cathode and anode in Ar gas space of HCFL lamp. We must find out the real cathode and anode in the lighted HCFL lamp. The lights are generated with moving electrons from cathode to anode. We must find out the formation of the real cathode and anode in Ar gas space of the lighted HCFL lamps under the AC driving circuit.

In general, the HCFL lamps brilliantly light up under the operation of the AC driving circuit that has AC $100 \mathrm{~V}$ with 50 (or 60) Hz. Figure 4(A) shows the photopicture of the lighted HCFL lamp. Figure 4(B) shows the waveform at the electrodes of the lighted HCFL lamp. The positive and negative potential of the waveforms are given by the potential against to grand (Earth) that has zero potential as shown in Figure 4(B). The waveforms are given by the change in the applied voltages as a function of the running time for $20 \mathrm{~ms}$ (=50 one cycle. The waveforms shown in Figure 4(B) clearly indicate us that the given electrode of the W-filament coil of the HCFL lamp at one side always has the positive potential for $10 \mathrm{~ms}$, and for the next half cycle, the $\mathrm{W}$-filament electrode at other side has the negative potential for following $10 \mathrm{~ms}$. The HCFL lamps never have the coexistence of the negative potential (cathode) and positive potential (anode) in the given half cycle $(10 \mathrm{~ms})$. This means that the $\mathrm{W}$-filament electrodes in the HCFL lamp never form the electric circuit for the moving electrons in the operation with each half cycle. 


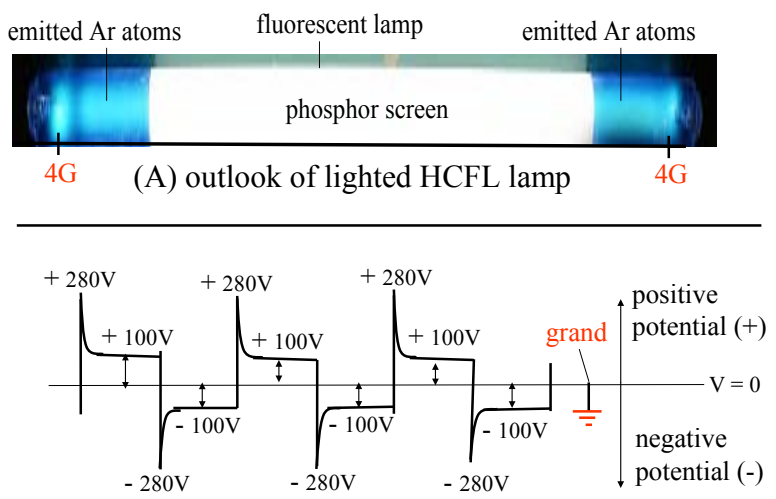

(B) waveform of applied potential to electrodes

Figure 4. Photopicture of lighting HCFL lamp and AC waveform of driving circuit.

For the formation of the electric circuit in the Ar gas, the coexistence of the cathode and anode in each half cycle $(10 \mathrm{~ms})$ is an essential necessity for lighting HCFL lamp. Then, the electrons move from the cathode to the anode. The moving electrons in the Ar gas space generate the visible lights. However, we cannot find the coexistence of the cathode and anode from the waveform shown in Figure 4(B). In the past for 90 years, no one described this basic point. Anyhow, the HCFL lamps brilliantly light up with the AC driving circuit. We must find out coexistence of cathode and anode for half cycle.

For the lighting of the HCFL lamps under the AC driving circuit, we must find out a pending subject of the lighting mechanism of the HCFL lamps. For finding out of the real lighting mechanism of the HCFL lamp, we have studied with the $\mathrm{W}$-filament coils, without the $\mathrm{BaO}$ particles. Unfortunately, we cannot light up the HCFL lamps without the $\mathrm{BaO}$ particles under the $\mathrm{AC}$ driving circuit. The subject of the lighting mechanisms in the HCFL lamps by the AC driving circuit steps in a most fundamental subject of the lighting mechanisms of the HCFL lamp. The fundamental subject should find the coexistence of the cathode and anode for each half cycle of the AC driving circuit.

For finding of the lighting mechanisms of the HCFL lamp under the AC driving circuit, we have studied with the $\mathrm{W}$-filament coil without the $\mathrm{BaO}$ particles under the optical microscope with the magnification higher than 50 times. Then we have found the interesting results. As the $\mathrm{W}$-filament coils at the positive potential heat up to the higher than $500^{\circ} \mathrm{C}$, the heated $\mathrm{W}$-filament coils are covered with the volume of the corona lights. We have assigned the volume of the corona light as the fourth generation electron source $(4 \mathrm{G})$. However, the $+4 \mathrm{G}$ electron source on the positive $\mathrm{W}$-filament coil disappears for the following half cycle. The $+4 \mathrm{G}$ volume discontinuously stay on the $\mathrm{W}$-filament coil of the positive side, as illustrated in Figure 5. We have the same story with the heated W-filament coil at the opposite side of the HCFL lamp that has the negative potential against to the grand. We also detect the volume of the corona light $(-4 \mathrm{G})$ 
on the $\mathrm{W}$-filament coil that has the negative potential for only half cycle. The volume of the $-4 \mathrm{G}$ corona light discontinuously holds for each half cycle in the AC operation as illustrated in Figure 5.

Figure 6 shows the photopicture of the working $\mathrm{W}$-filament coils with the $\mathrm{BaO}$ particles at the both ends. We have found that the large volume of the $\mathrm{Ar}$ gas at around the heated bear spot continuously lights up with the sky-blue lights with the help of the heated $\mathrm{BaO}$ particles that have the large heat capacity. Thus, the $\pm 4 \mathrm{G}$ volumes continuously presence on the $\mathrm{W}$-filament coils for one cycle. As shown in the photographs in Figure 6, the lighted volume and shape are changed with the variation of the bear spots in the $\mathrm{W}$-filament coils with the $\mathrm{BaO}$ particles. The variations in the sizes and figures of the $\pm 4 \mathrm{G}$ volumes are caused with the uncontrolled condition of the preparation of the $\mathrm{W}$-filament coils with the $\mathrm{BaO}$ particles. This is because the developers of the HCFL lamps do not understand the formation mechanisms of the $\pm 4 \mathrm{G}$ volumes on the heated bear spot under the help of the heated $\mathrm{BaO}$ particles. However, the variations of

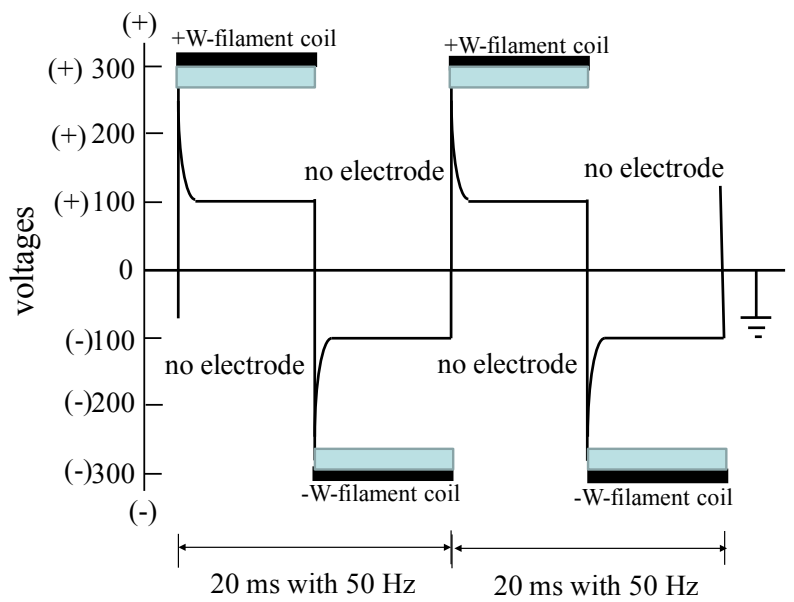

Figure 5. Formed volumes of corona light $(4 \mathrm{G})$ on respectively heated $\mathrm{W}$-filament coils at positive potential (+) and negative potential (-) for each half. But they are not coexist in each half cycle.

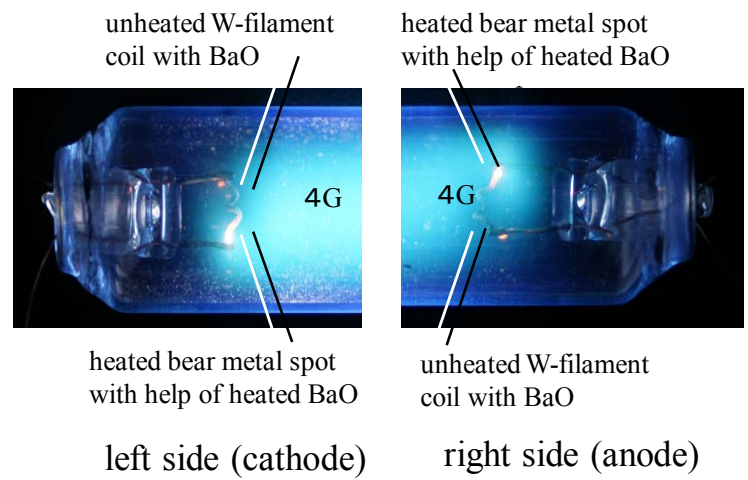

Figure 6. Photopictures of heated spots of working $\mathrm{W}$-filament coils at the both end of HCFL lamp. Ar atoms in heated volume at around heated spots are ionized with electric field from $\mathrm{W}$-filament coils. 
the sizes and figures of the $\pm 4 \mathrm{G}$ volume are not serious troubles for the operation of the HCFL lamps. For the mass production of the HCFL lamps, it is a better way that the size and shape of the $4 \mathrm{G}$ volumes should be under the quality control of the HCFL lamps.

Then we have found the continuous formation mechanisms of the $\pm 4 \mathrm{G}$ volumes for one cycle. The details of the formation of the $\pm 4 \mathrm{G}$ volumes for one cycle, not the half cycle, at around the $\mathrm{W}$-filament electrodes are below. The thermal radiation from the heated bear spot selectively heats up the limited volume of the Ar atoms at around the bear spot of the $\mathrm{W}$-filament coil to a temperature at about $80^{\circ} \mathrm{C}$ that is determined by the infrared thermometer. With the limited $\mathrm{BaO}$ particles at around heated bear spots also heat up by the heat conduction from the heated bear spot of the $\mathrm{W}$-filament coil. Since the heated $\mathrm{BaO}$ particles have the large heat capacitance, the heated $\mathrm{BaO}$ particles hold the temperature for the unheated half cycle. Therefore, the $4 \mathrm{G}$ volume at around the bear spot continuously hold the required temperature for one cycle (for $20 \mathrm{~ms}$ ) with the help of the heated $\mathrm{BaO}$ particles at nearby the heated bear spot of the $\mathrm{W}$-filament coil. The heated volumes at around the $\mathrm{W}$-filament coils are ionized by the electric fields from the $\mathrm{W}$-filament coils for the formation of $\pm 4 \mathrm{G}$.

The ionization of the Ar atoms in the unheated Ar gas requires the high electric filed. With this reason, only Ar atoms in the heated volume are selectively ionized under the electric field $\left(\mathrm{F}_{\text {flam }}\right)$ from the $\mathrm{W}$-filament coil for a half cycle. And the $4 \mathrm{G}$ volume holds for the following half cycle with the help of the heated $\mathrm{BaO}$ particles at the nearby the heated spot. The results show that the $\pm 4 \mathrm{G}$ volumes continuously form on the W-filament coils at the both ends of the HCFL lamps for one cycle, as shown in Figure 7. The $\pm 4 \mathrm{G}$ volumes on the negative and positive $\mathrm{W}$-filament coils respectively act the electron sources (cathode) and electron correction source (anode). Thus the HCFL lamps have the DC internal electron source under the help of the external AC driving circuit.

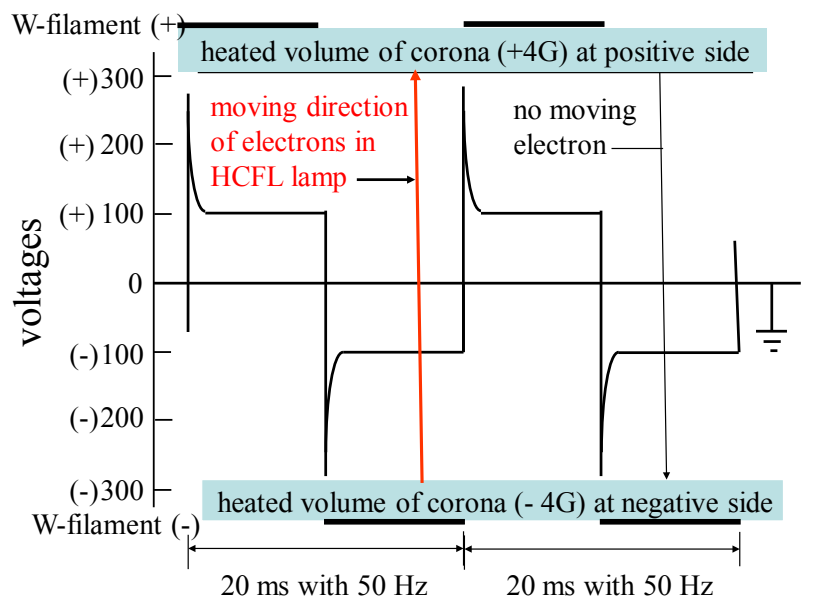

Figure 7. Continuous formations of $\pm 4 \mathrm{G}$ volumes on negative and positive $\mathrm{W}$-filament coil which are operated with AC driving Lights. Lights are generated by moving electrons from cathode to anode in internal DC driving circuit which is formed with $\pm 4 \mathrm{G}$ volumes in Ar gas space. 
Now we will describe the details of the Ar atoms in the heated $\pm 4 \mathrm{G}$ volumes on the $\mathrm{W}$-filament coils under the operation with the $\mathrm{AC}$ driving circuit with $100 \mathrm{~V}, 50 \mathrm{~Hz}$. The heated volumes contain a large amount of $\mathrm{Ar}^{1+}$, free electrons $\left(\mathrm{e}^{-}\right)$, and excited $\mathrm{Ar}$ atoms $\left(\mathrm{Ar}^{*}\right)$. The $\mathrm{Ar}^{1+}$ and $\mathrm{e}^{-}$are the same numbers. The numbers of $\mathrm{Ar}^{*}$ are less than 0.08 of $\mathrm{Ar}^{1+}$ [1]. The majorities in the $\pm 4 \mathrm{G}$ volume are the invisible $\mathrm{Ar}^{1+}$ and $\mathrm{e}^{-}$. Mass of $\mathrm{Ar}^{1+}$ is $1.6 \times 10^{-27} \mathrm{~kg}$, and mass of electron is $9.1 \times 10^{-31} \mathrm{~kg}$. The presence of $\mathrm{Ar}^{1+}$ neutralizes the negative electric field in the $\pm 4 \mathrm{G}$ volume. Therefore, only electrons in the $-4 \mathrm{G}$ volume (i.e., cathode) smoothly move on in the neutralized vacuum under the $\mathrm{DC}$ electric field $\left(\mathrm{F}_{\mathrm{DC}}\right)$ between cathode and anode in the HCFL lamps. This means that only electrons in the $-4 \mathrm{G}$ volume, which is formed on the negative potential of the $\mathrm{W}$-filament coil, act as the electron source (cathode) in the Ar gas space. The $+4 \mathrm{G}$ volume on the positive $\mathrm{W}$-filament coil only acts as the anode that correct arrived electrons from the Ar gas space. Thus, the $\pm 4 \mathrm{G}$ volumes on the $\mathrm{W}$-filament coils at the both ends act as the cathode and anode of the internal DC driving circuit. Thus, we have found the formation of the internal DC electric circuit in front of the $\mathrm{W}$-filament coils, without the electron flow from the $\mathrm{W}$-filament coil to the $\pm 4 \mathrm{G}$ volumes.

We have theoretically and experimentally solved the difficulty of the holding of the $\pm 4 \mathrm{G}$ volumes for one cycle under the operation of the AC driving circuit with the concept of Townsend. Two disparate electric circuits, the external AC driving circuit and the internal DC electric circuit, involve in the operation of the HCFL lamp. The lights from the HCFL lamp are generated with the moving electrons from the cathode to the anode in the internal DC electric circuit formed in the Ar gas space, as illustrated in Figure 7. The electrodes of the external AC driving circuit only help the formation of the internal DC electric circuit by the electric field from the electrodes.

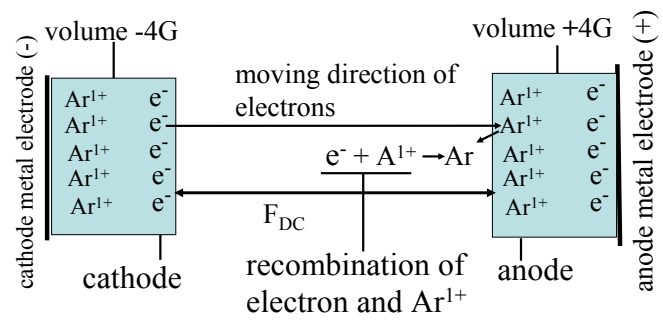

Figure 8. Schematic illustration of distribution of $\mathrm{Ar}^{1+}$ and $\mathrm{e}^{-}$in volumes of corona light $(4 \mathrm{Gs})$ and moving direction of electrons between cathode and anode. Arrived electron recombines with $\mathrm{Ar}^{1+}$ and returns to $\mathrm{Ar}$ atom.

Figure 8 illustrates the details, with the atomic levels, of the internal DC driving circuit formed in the lighted HCFL lamp. The $\mathrm{e}^{-}$and $\mathrm{Ar}^{1+}$ in the $\pm 4 \mathrm{G}$ volume are not uniformly distributed in the $\pm 4 \mathrm{G}$ volumes. The electric field from the negative metal electrode (-) attracts the $\mathrm{Ar}^{1+}$, but the negative metal electrode does not take out the $\mathrm{Ar}^{1+}$ from the $-4 \mathrm{G}$ volume. The attracted $\mathrm{Ar}^{1+}$ stays in the surface area of the $+4 \mathrm{G}$ volume as illustrated in Figure 8 . 
The negative metal electrode repulses the electrons in the $-4 \mathrm{G}$ volume. The repulsed electrons distribute to far from the metal electrode in the $-4 \mathrm{G}$ volume. The electric field, $\mathrm{F}_{\mathrm{DC}}$ may smoothly take out the electrons from the $-4 \mathrm{G}$ volume as illustrated in Figure 8. The taken out electrons step in the nearby the volume of the $4 \mathrm{G}$ and ionize the $\mathrm{Ar}$ atoms $\left(\mathrm{Ar}^{1+}\right)$. The negative electric field at the nearby $-4 \mathrm{G}$ volume is neutralized with the presence of $\mathrm{Ar}^{1+}$. The neutralization of the negative field in the Ar gas in the HCFL lamp propagates with the moving speed of the electrons from the $-4 \mathrm{G}$ volume. All of the following electrons from the $-4 \mathrm{G}$ volume move to the neutralized vacuum in the Ar gas space to the anode. Arrived electrons to the $+4 \mathrm{G}$ volume are recombined with the $\mathrm{Ar}^{1+}$. The recombined electron with $\mathrm{Ar}^{1+}$ returns to $\mathrm{Ar}$ atom.

The HCFL lamps actually light up with the moving electrons between the cathode of the $-4 \mathrm{G}$ volume to the anode of the $+4 \mathrm{G}$ volume, as illustrate in Figure 9(B). There is no consumption of the Ar atoms and electrons in the lighted HCFL lamps, promising the long operation life. The operation life of the HCFL lamps is determined by the evaporation of the $\mathrm{W}$-atoms from the heated bear spot in the W-filament coil. The operation life of the HCFL lamps is around 500 hours with operation with $50 \mathrm{~Hz}$. The operation life extends to $10^{4}$ hours by the operation with $30 \mathrm{kHz}$.

\section{Electrodes of External AC Driving Circuit Detect Induced Voltages of $\mathrm{C}_{\mathrm{FL}}$}

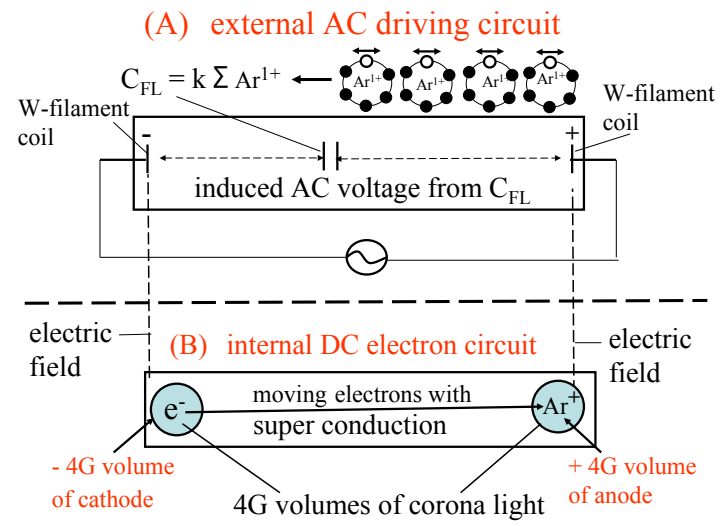

Figure 9. Schematic illustration of coexistence of disparities of external AC driving circuit and internal DC driving circuit in lighted HCFL lamp. Two disparate electric circuits are conjugated with electric field without electron flow.

There is a large deference of the electric currents between the external AC electric circuit and internal DC electric circuits. The W-filament electrodes of the external AC driving circuit only pick up the induced voltages from the capacitor $\mathrm{C}_{\mathrm{FL}}$ as illustrated in Figure $9(\mathrm{~A})$. The $\mathrm{C}_{\mathrm{FL}}$ is formed with the synchronous displacement of the electrons within the upper ${ }^{3} \mathrm{p}_{6}$ electron shell of the $\mathrm{Ar}^{1+}$ under the AC driving circuit. However, the detected induced voltage hysterically has been called as the induced AC current in the established reports [5] [6] [7] [8] 
[9]. This is a mistake in the study of the AC driving circuit of the HCFL lamps. The capacitance of the $\mathrm{C}_{\mathrm{FL}}$ changes with the numbers of $\mathrm{Ar}^{1+}$ atoms in the lighted HCFL lamps: a high capacitance with the high Ar gas pressures. It is now clear for us. The power consumption of the external AC driving circuit does not relate with the generation energy of the lights from HCFL lamps.

\section{No Poison of Hg Atoms in FL Lamps to Human Body}

Here arises the political action for study of FL lamps. The Japanese Government recently prohibits the production of the FL lamps as the poison of $\mathrm{Hg}$ atoms to human body, using the Minemata Disease. Then, the Japanese Government has proposed to United Nation for the termination of the FL lamps on the World.

The poison of the Hg atoms in the FL lamps is a false story as the science. The Minemata Disease is caused with the organic $\mathrm{Hg}$ compound $\left(\mathrm{CH}_{3} \mathrm{HgX}\right)(11,1)$. The Hg droplets in the FL lamps are safe for human body. The Japanese Governments must withdraw their proposal from UN. The FL lamps hold an incomputable advantage over the LED lamps as described in this report.

\section{Conclusions}

The lighting mechanisms of the established HCFL lamps have been analyzed. The HCFL lamps contain Ar gas at $931 \mathrm{~Pa}$ (7 Torr). Ar atoms float in vacuum with separation distance with $10^{-6} \mathrm{~m}$. The vacuum between floating Ar atoms fills up with the negative electric field with electrons in ${ }^{3} \mathrm{p}_{6}$ orbital shell of Ar atom. The established HCFL lamps neglect this fact. Then, they have assumed that the heated $\mathrm{BaO}$ particles on the $\mathrm{W}$-filament coils directly emit thermoelectrons in to the Ar gas space. This is also a false story [11].

Furthermore, the HCFL lamps are operated with the AC driving circuit with $50 \mathrm{~Hz}$. Under the AC driving circuit, the polarity of the electrode at one side of HCFL lamp is periodically, but discontinuously, changed for each half cycle. The electrodes of the HCFL lamp do not have the coexistence of the positive and negative potential in a half cycle $(10 \mathrm{~ms})$, resulting in no formation of the electric circuit based on the electrons.

We have found that the HCFL lamps are operated with the coexistence of the disparate external AC driving circuit and internal DC driving circuit. There is no electric current between them. They are conjugated with the electric field from the AC driving circuit. In the vacuum with the Ar gas, the cathode emits the electrons and the anode received the arrived electrons. The cathode and anode of the internal DC driving circuit of the HCFL lamp are respectively formed with the volumes of the $\pm 4 \mathrm{G}$ corona lights on the $\mathrm{W}$-filament coil electrodes at both ends of the HCFL lamps. The moving electrons from the cathode $(-4 \mathrm{G})$ ionize $\mathrm{Ar}$ atoms $\left(\mathrm{Ar}^{1+}\right)$ which neutralize the negative electric field between floating $\mathrm{Ar}$ atoms with the moving speed of the electrons under the electric field, $\mathrm{F}_{\mathrm{DC}}$ between cathode and anode of the $\pm 4 \mathrm{G}$. The neutralized vacuum between $\mathrm{Ar}$ atoms becomes the superconductive vacuum; that is no electric resistance $(\mathrm{R}=$ 
$0)$. The superconductive vacuum at the temperature higher than room temperature is a great advantage over other incandescent lamps, like LED lamps that have the electric resistance. The demerit of the HCFL lamps is operation life for 500 hours under the $50 \mathrm{~Hz}$ operation, and for around $10^{4}$ hours under the 30 $\mathrm{kHz}$ operation. The extension of the operation life of the FL lamps remains as the subject for a future study.

\section{Conflicts of Interest}

The author declares no conflicts of interest regarding the publication of this paper.

\section{References}

[1] Ozawa, L. (2015) Coil-EEFL Tube as Supreme Incandescent Light Source with Zero Electric Power Consumption, Astronomical Quantum Efficiency, and Long Life. Global Journal of Science Frontier Research: A, Physics and Space Science, 16, 16-50.

[2] Ozawa, L. (2018) An Invention of Coil-EEFL Lamps Operated with $\mathrm{W}_{\mathrm{DC}}=0$ for a Great Contribution to Green Energy Project of UN. Open Access Journal of Physics, 11, 1-16.

[3] Machelet, R.R. (1926) US Pat. 1,612,387.

[4] Meyer, F. (1928) US Pat. 2,182,732.

[5] Waymouth, J.F. (1971) Electron Discharge Lamp. MIT Press, Cambridge, Mass.

[6] Flower, R.H. and Nordheim, L.W. (1928) Electron Emission in Intense Electric Fields. Proceedings of the Royal Society A, 119, 173.

https://doi.org/10.1098/rspa.1928.0091

[7] (1973) Handbook of Electric Discharge Lamps. Japanese Institute of Electric Engs,

[8] (2003) Handbook of Physics and Chemistry. CRC Press, Taylor \& Francis Group, Boca Raton, London, New York.

[9] Shionoya, S. and Yen, W.M., Eds. (1998) Phosphor Hand Book. CRC Press, Taylor Francis Group, Boca Raton.

[10] American Institute of Physics (1993) American Vacuum Society Classics, (1) The Fundamental Data on Electrical Discharge Gases, (2) Field Emission and Field Ionization, (3) Vacuum Technology and Space Simulation, (4) The Physical Basics of Ultrahigh Vacuum, (5) Handbook of Electron Tube and Vacuum Techniques, (6) Vacuum Sealing Techniques, and (7) Ionized Gases.

[11] (1987) Handbook of Physics and Chemistry. Iwanami Publishing, Tokyo. 